Goldschmidt 2021 Abstract

https://doi.org/10.7185/gold2021.6366

\section{Unravelling (Ba,Sr)SO 4 oscillatory zoning: A lab-on-a-chip approach integrating in-situ characterisation and reactive transport modelling diagnostics}

\author{
JENNA POONOOSAMY ${ }^{1}$, MOHAMED MAHROUS ${ }^{2}$, ENZO \\ CURTI $^{3}$, DIRK BOSBACH ${ }^{1}$, SERGEY V CHURAKOV ${ }^{4}$, \\ GUIDO DEISSMANN ${ }^{1}$, THORSTEN GEISLER ${ }^{5}$ AND \\ NIKOLAOS I PRASIANAKIS ${ }^{6}$ \\ ${ }^{1}$ Forschungszentrum Jülich GmbH \\ ${ }^{2}$ Paul Scherrer Institute \\ ${ }^{3}$ Paul Scherrer Institut \\ ${ }^{4}$ Paul Scherrer Institut, Switzerland \\ ${ }^{5}$ Rheinische Friedrich-Wilhems-Universität Bonn \\ ${ }^{6}$ Paul Scherrer Institut, PSI \\ Presenting Author: j.poonoosamy@fz-juelich.de
}

The co-precipitation of sulphate minerals such as celestine and baryte is widely studied because their formation is ubiquitous in natural and anthropogenic systems. Co-precipitation in porous media results in crystallisation of solid solutions yielding characteristics that are rarely observed in bulk solution or in batch experiments such as oscillatory zoning. In previous experiments formation of compositionally-zoned (Ba,Sr) $\mathrm{SO}_{4}$ crystals was observed post-mortem in macroscopic silica gel counter-diffusion experiments ${ }^{1}$. The formation of zoned crystals was originally explained by the difference in the solubility products of the end-members combined with diffusion-limited transport of solutes to the mineral-fluid interface ${ }^{1}$ while a later study favored the idea of kinetically controlled reactions ${ }^{2}$. With recent advances combining in-operando microfluidic experiments and pore-scale modelling, it is now possible to verify hypotheses on the driving forces of transport-coupled geochemical processes ${ }^{3,4}$. We developed a "lab on a chip" experiment that enabled the systematic study of the nucleation and growth of oscillatory-zoned $(\mathrm{Ba}, \mathrm{Sr}) \mathrm{SO}_{4}$ crystals in a microfluidic chamber. Our micromodel consists of two parallel supply channels interconnected by microfluidic reaction chambers. $\mathrm{A} \mathrm{Na}_{2} \mathrm{SO}_{4}$ solution and a mixed solution of $\mathrm{BaCl}_{2}$ and $\mathrm{SrCl}_{2}$ were injected into the supply channels. The coprecipitation of $(\mathrm{Ba}, \mathrm{Sr}) \mathrm{SO}_{4}$ was fostered by the counter diffusion of solutes in the microfluidic reaction chamber. The compositions of the solid solutions were determined by in-situ Raman spectroscopy. We used reactive transport modelling with newly implemented theoretical approaches such as the supersaturation function ${ }^{5}$ and classical nucleation theory ${ }^{6}$ (CNT) extended to solid solutions to (i) predict the composition of the nucleating phases, and (ii) determine the driving forces for the oscillatory zoning. Our investigation shows that the composition of the nucleating phases can be approximated by using CNT and that the oscillatory zoning results from a combination of limited diffusional transport of solutes and kinetically controlled precipitation reactions.
${ }^{1}$ Putnis et al. 1992 Nature

${ }^{2}$ Pina \& Putnis 2001 Geochim. Cosmochim. Acta

${ }^{3}$ Poonoosamy et al. 2019 Chem. Geol.

${ }^{4}$ Prasianakis et al. 2020 Geochim. Cosmochim. Acta

${ }^{5}$ Prieto 2009 Rev. Mineral. Geochem.

${ }^{6}$ Noguera et al. 2016 Chem. Geol. 